\title{
COMPETIÇÃO DE PONTES: ESTUDANTES EM PROL DE UM PROJETO DE ENSINO
}

DOI: 10.37702/2175-957X.COBENGE.2021.3389

Lucas Henrique da Silva Coelho - lucashcoelho@ymail.com

UFSJ

Avenida Helder Candreva Rossi 267

36416-200 - Congonhas - MG

Letícia Gabrielle Esteves Cardozo - leticia.esteves15@outlook.com

UFSJ

Rua São Cristóvão 501

36412-334 - Congonhas - MG

Alexandre da Silva Galvão - asgalvao@ufsj.edu.br

UFS

R Amaro da Silveira 321

36420-000 - Ouro Branco - MG

Resumo: A construção de modelos reduzidos de pontes em palitos de picolé vem sendo aplicada como uma metodologia de ensino em diversas instituições educacionais brasileiras. O presente trabalho relata a organização e o desenvolvimento de uma competição de pontes de palitos no curso de Engenharia Civil da Universidade Federal de São João Del Rei, durante os períodos letivos de 2018/2 a 2019/2. A iniciativa advém dos alunos do centro acadêmico do curso. Uma pesquisa foi realizada para comprovar o progresso do evento e seu potencial de impactar positivamente, tanto alunos organizadores, quanto competidores. Foi comprovado o seu papel como método de aprendizagem para consolidação dos conhecimentos relacionados as áreas de estruturas, adquiridos pelos estudantes no curso, através da aplicação de conceitos teóricos na prática.

Palavras-chave: Ensino. Engenharia. Competição. Pontes de palitos. Centro acadêmico. 


\section{INTRODUÇÃO}

A construção de modelos reduzidos de pontes em palitos de picolé vem sendo aplicado como uma metodologia de ensino em diversas instituições educacionais brasileiras. Isto se deve ao fato de proporcionar aos alunos, uma oportunidade da aplicação de conceitos teóricos em situações práticas, contribuindo para assimilação do conteúdo das disciplinas relacionadas ao tema, melhorando o seu processo de aprendizagem.

Conforme apontado por Kripka et al. (2018), a proposta de metodologia de ensino que envolve a construção de estruturas em escala reduzida, como no caso das pontes de palitos, é capaz de favorecer a consolidação dos conhecimentos relacionados as áreas de estruturas, adquiridos pelos estudantes em cursos de engenharia civil, por exemplo. Apesar da aparente simplicidade em se construir uma ponte de palitos, o processo requer que o estudante faça uma avaliação prévia das propriedades do material a ser empregado, que analise estruturalmente a geometria escolhida, bem como o comportamento da estrutura devido as solicitações geradas pelas cargas, até o seu rompimento.

Além disso, a experiência através dessa metodologia possibilita aos discentes que desenvolvam habilidades para resolução criativa de problemas, estimulando o emprego de seus conhecimentos através de uma análise crítica, e na interação do trabalho em equipe. Conforme Moreira (2019), dar aos estudantes situações em que é preciso a tomada de decisões por conta própria, em busca de um objetivo traçado, contribui para a sua autonomia, no pensar e no agir diante de desafios.

Assim, este trabalho tem o intuito de apresentar a Competição de Pontes, um projeto de evento acadêmico que já possui três edições realizadas. $E$ que tem como proposta, o projeto da construção e o teste de carga de uma ponte treliçada em palitos de picolés. Este evento é destinado principalmente aos estudantes no curso de Engenharia Civil, também aberto aos demais estudantes dos cursos na unidade educacional do Campus Alto Paraopeba, da Universidade Federal de São João Del-Rei (UFSJ), localizado na cidade de Ouro Branco em Minas Gerais.

A Competição de Pontes é um evento promovido pelo Centro Acadêmico de Engenharia Civil (CAEC), a entidade responsável por representar os estudantes do curso perante a universidade. Este evento tem sido realizado com o envolvimento da disciplina de Mecânica Vetorial do quarto período do curso, para aproximar ainda mais os estudantes da oportunidade de aplicar na prática os conceitos teóricos adquiridos.

Em sua primeira edição, a Competição de Pontes aconteceu como parte do evento comemorativo dos 10 anos do curso de Engenharia Civil, que ocorreu ao final do ano de 2018, Figura 1. 


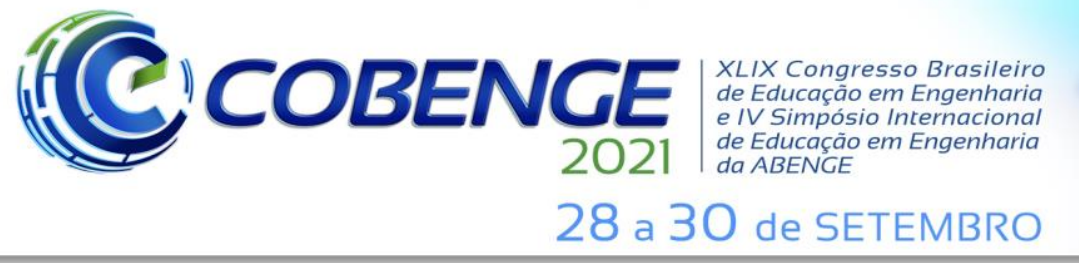

\section{Evento Online}

"Formaçāo em Engenharia: Tecnologia, Inovação e Sustentabilidade"

Figura 1 - Primeira Competição de Pontes.

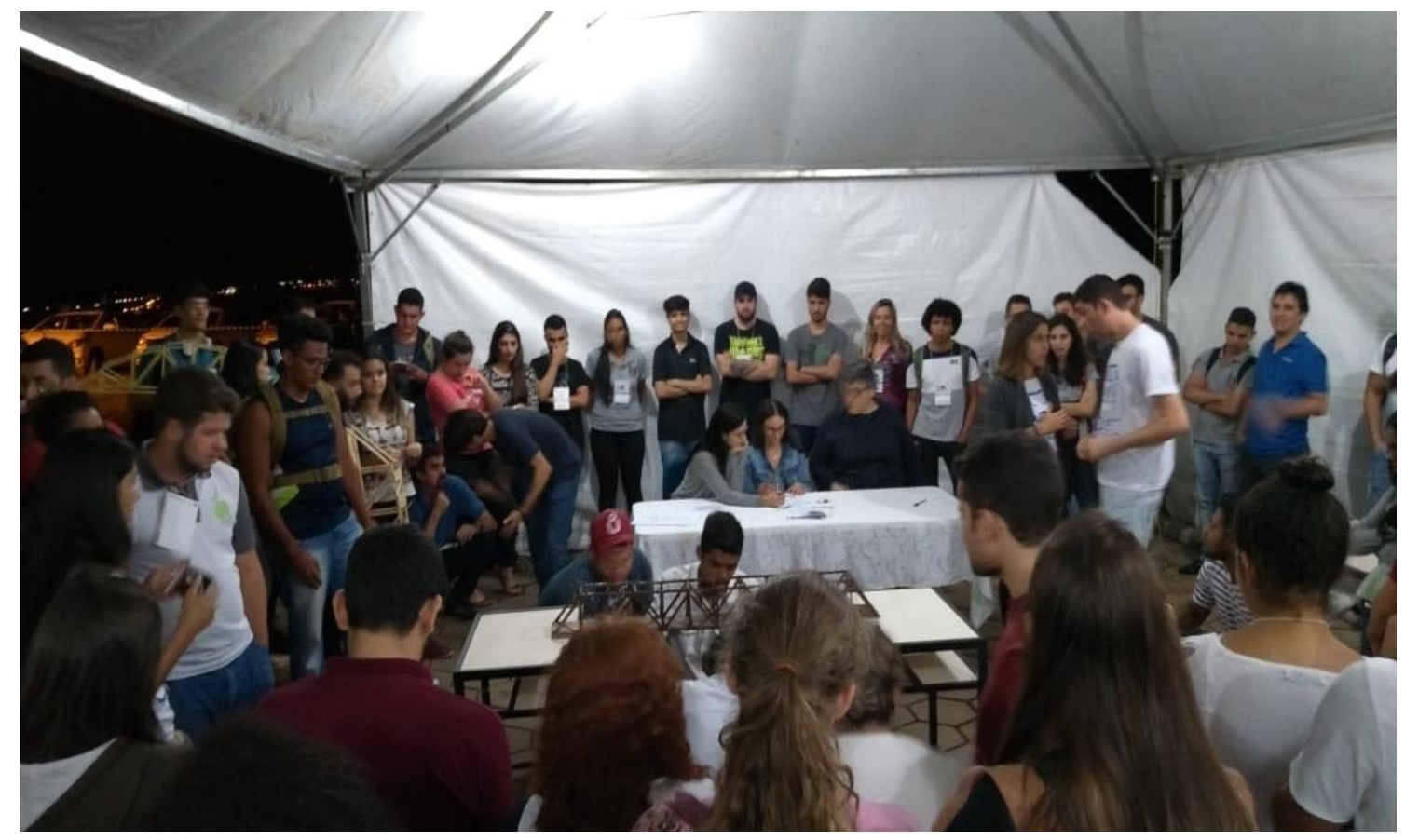

Fonte: Acervo CAEC - Competição de Pontes Semestre 2018/1.

Diante da repercussão positiva da competição, tanto para o entretenimento de seus expectadores, como para o aprendizado de seus participantes, definiu-se pela continuidade do projeto. Deste então, foram realizadas mais duas edições da Competição de Pontes, nos dois semestres letivos do ano de 2019, como mostrado na Figura 2 e na Figura 3.

Figura 2 - Segunda Competição de Pontes.

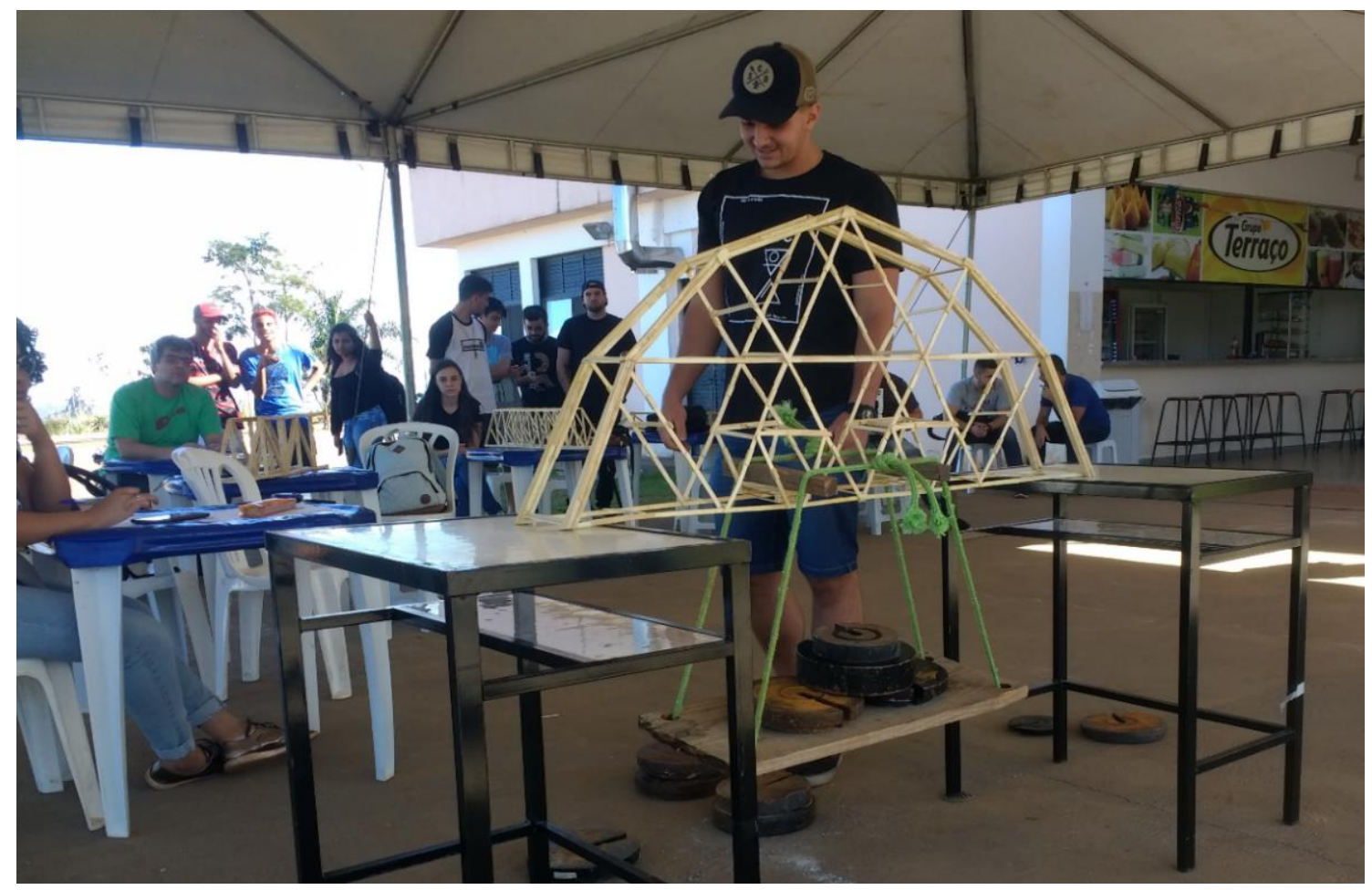

Fonte: Acervo CAEC - Competição de Pontes Semestre 2019/1. 
Figura 3 - Terceira Competição de Pontes.

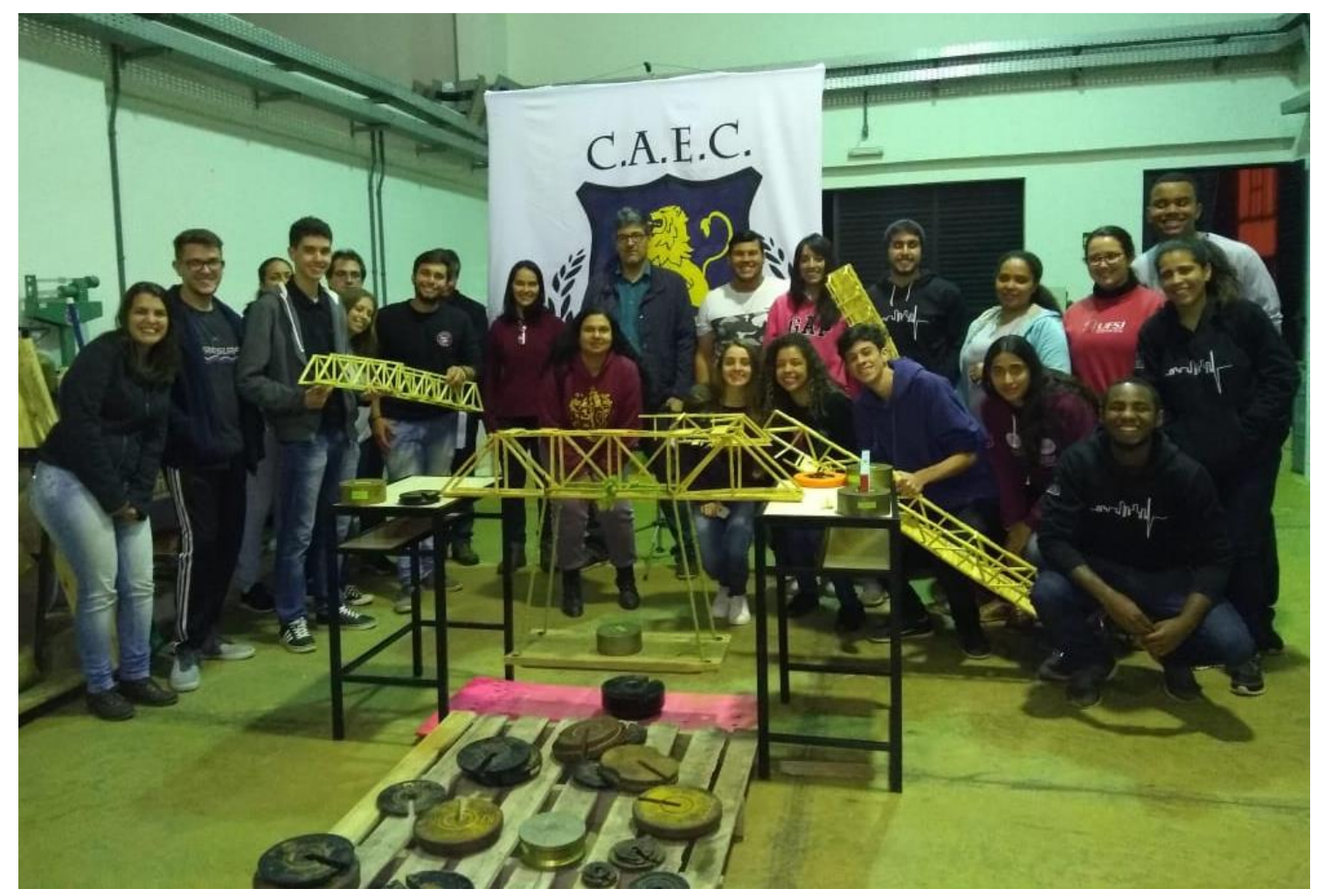

Fonte: Acervo CAEC - Competição de Pontes Semestre 2019/2.

\section{OBJETIVOS}

A Competição de Pontes tem como objetivo principal proporcionar aos estudantes uma situação que favoreça a aprendizagem, através da aplicação prática de conceitos teóricos vistos nas disciplinas do curso de Engenharia Civil. Dentre os demais objetivos, temos:

- Projetar e construir um modelo reduzido de uma ponte treliçada;

- Incentivar o trabalho em equipe e a criatividade na resolução de desafios;

- Estimular a capacidade de análise crítica dos estudantes envolvidos;

- Promover um evento interessante de entretenimento;

- Contribuir positivamente para o curso de Engenharia Civil.

\section{METODOLOGIA}

A organização da competição foi feita pelos alunos do Centro Acadêmico de Engenharia Civil da UFSJ. Dentre as atividades que cabe a organização está a escrita do edital, para a padronização da participação dos competidores, definição dos critérios de avaliação das pontes e seus testes de carga. Definido o prazo para a inscrição das equipes, elas precisavam informar os nomes de seus integrantes e o nome da ponte para identificação.

$\mathrm{O}$ centro acadêmico define a data e o local do teste de carga em conjunto com o professor da disciplina de Mecânica Vetorial, uma vez que as pontes de palitos fazem parte da avaliação da disciplina. Um material de divulgação é criado pelos alunos organizadores 
para incentivar os discentes de outros períodos a competirem. Os organizadores também ficam incumbidos de definir um prêmio para a equipe campeã. O que não deixa de ser uma forma de motivar e instigar o espírito competitivo entre os estudantes, já que o intuito da ponte é obter a maior carga de ruptura, com o menor peso, ou seja, a máxima eficiência.

No dia dos testes, as pontes foram identificadas com seus respectivos nomes. Em seguida, os organizadores mesuraram o peso das pontes, uma vez que ele é uma das variáveis para a nota de eficiência. Feita a pesagem, as pontes são expostas para que os professores convidados, na condição de avaliadores, possam dar suas notas no critério de estética. Eram escolhidos os docentes envolvidos nas disciplinas da área de estruturas do curso. Desta forma, além de avaliar as pontes eles também contribuíam com comentários sobre a concepção estrutural dos modelos e sobre os resultados dos testes de carga. Sempre relacionando com os conceitos de suas respectivas disciplinas.

Passado este processo, inicia a aplicação das cargas por ordem de inscrição. O resultado da competição era divulgado alguns dias depois, após análise dos resultados e de casos omissos por parte dos alunos organizadores.

\subsection{Mudanças no edital}

Ao decorrer das três edições da competição, o edital sofreu alterações por parte da organização. Essas alterações vinham com o intuito de adequar o evento para a realidade e estrutura do Campus Alto Paraopeba, bem como melhorar a experiência dos alunos participantes.

O primeiro edital e seus critérios de avaliação foram baseados em competições de outras universidades e adaptado para a realidade dos estudantes do campus. Dentre as considerações deste primeiro edital, podemos destacar o método de avaliação sendo 10 pontos a nota máxima. Foram definidos quatro critérios: Estética 2,0 pontos; Estimativa do valor de colapso 2,0 pontos; Eficiência estrutural 3,0 pontos; Carga Máxima 3,0 pontos. A ponte que obtiver a maior soma dos critérios é declarada a campeã.

$\mathrm{Na}$ primeira edição do evento, percebeu-se a presença de pontes consideradas hiperestáticas, pelos docentes avaliadores. Como os discentes ainda não haviam estudado a disciplina de Estruturas Isostáticas, eles não possuíam conhecimentos para realizar esta análise durante a concepção estrutural da ponte. Assim, os alunos organizadores do evento incluíram no edital a Equação (1) para que os alunos pudessem realizar a conferência da treliça.

$$
b+r=2 n
$$

Para que a ponte seja considerada isostática o número de barras $(b)$ mais o número de reações externas $(r)$ deve ser igual a duas vezes o número de rótulas $(n)$, caso contrário, a ponte pode ser considerada hipostática ou hiperestática.

Outra mudança entre o edital da primeira edição da competição para a terceira edição foi a realização do teste de carga. Na primeira edição eram os organizadores do evento os responsáveis pela adição de carga nas pontes. A partir daí, observou-se que havia questionamentos por parte dos competidores quanto ao posicionamento da aplicação das cargas ou da forma que elas eram apoiadas no aparato de teste. Tais indagações, evidenciaram o espírito competitivo dos estudantes e influenciou para que no edital da terceira adição fosse incluído que cada grupo era responsável por indicar um de seus membros para a realização dos carregamentos. 


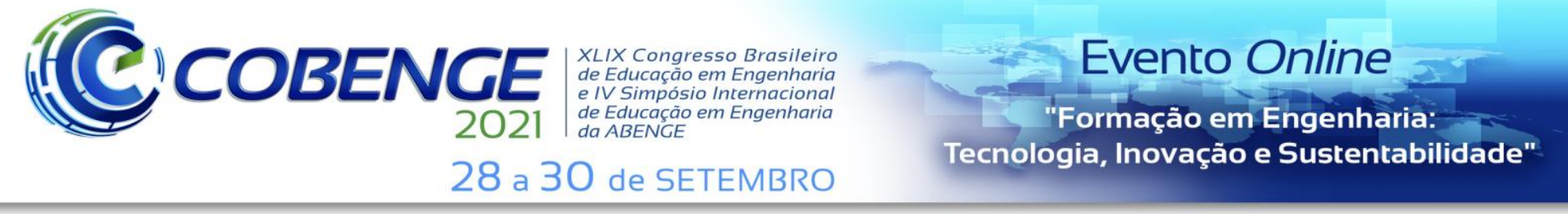

\subsection{Teste de Carga}

Este tópico se dedica na demonstração das melhorias e desafios encontrados pelos organizadores para realização dos testes de carga no espaço do Campus Alto Paraopeba.

Para a realização dos testes de carga, na primeira edição foi improvisado um cesto. Conforme ilustrado na Figura 4, este cesto era amarrado com cordas entre as treliças da ponte, de forma a manter um equilíbrio e não causar uma rotação no momento da aplicação das cargas.

Este método causou dificuldades no momento de troca das pontes, exigindo agilidade dos organizadores do evento. A colocação dos pesos também era dificultada pelo formato do cesto, exigindo preparo físico do organizador responsável por adicionar as cargas. Além disso, avaliou-se que o ponto em que a corda exercia tensão nas pontes era, na maioria das vezes, diferente do local de aplicação das cargas feito no cálculo estrutural de cada grupo.

Para a segunda e terceira edição foi feito um novo aparato para os testes de carga. Desta vez, foi preparada uma tábua de $30 \mathrm{~mm}$ de espessura, com furos em suas extremidades, de forma que uma corda pudesse passar entre eles e facilitar a colocação da ponte a ser avaliada. Utilizou-se dois pedaços de vergalhão, que ficavam apoiados nos banzos inferiores das pontes, permitindo que o aparato fosse colocado o mais próximo possível dos pontos onde os grupos aplicaram seus carregamentos de cálculo. Este aparado foi construído no próprio laboratório do curso de engenharia civil, com auxílio dos técnicos. Na Figura 5 é demonstrado o aparato descrito.

Figura 4 - Inserção de cargas nas pontes da primeira edição.

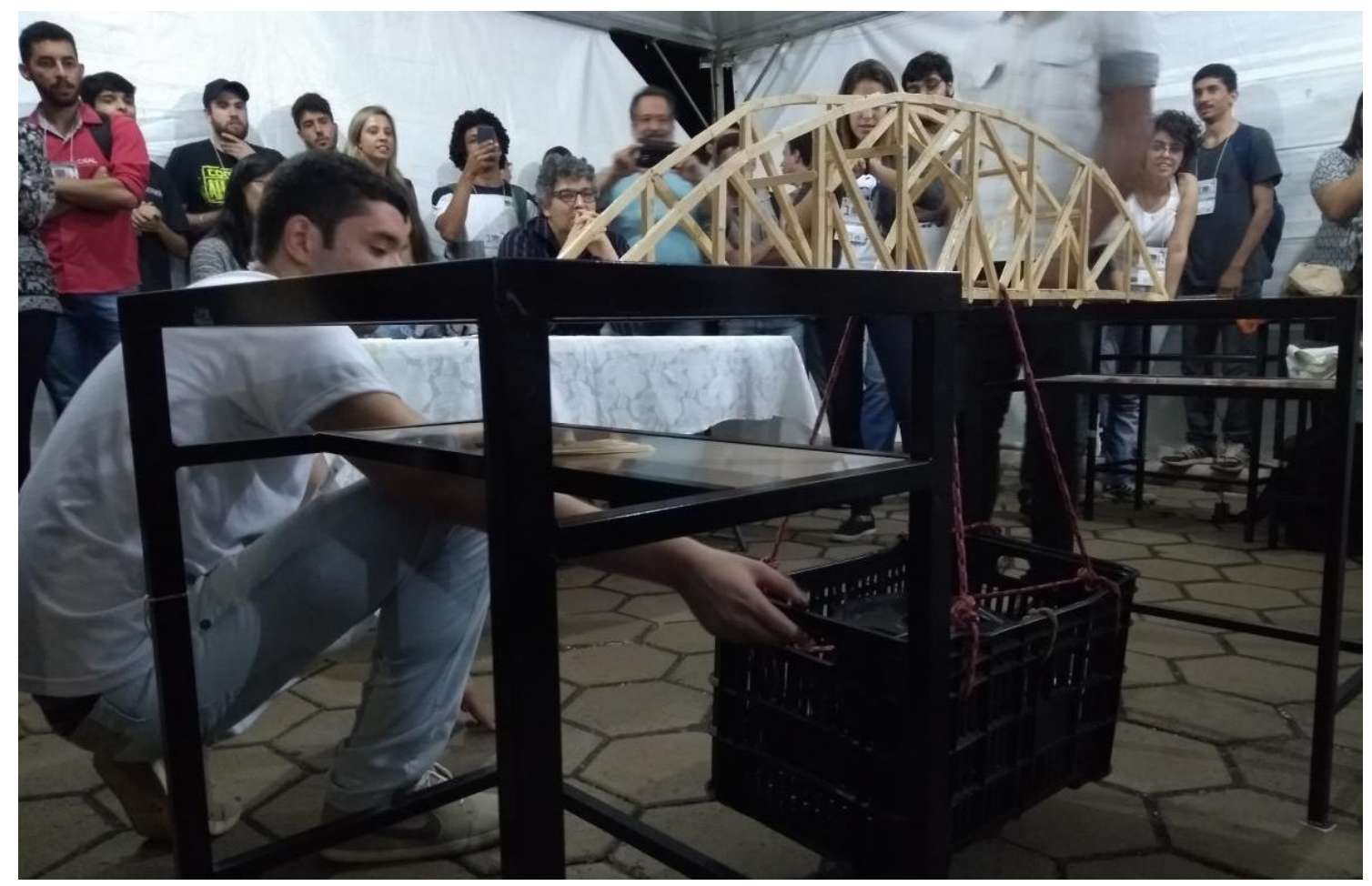

Fonte: Acervo CAEC - Competição de Pontes Semestre 2018/2. 


\section{COBENCE

Figura 5 - Inserção de cargas nas pontes da terceira edição.

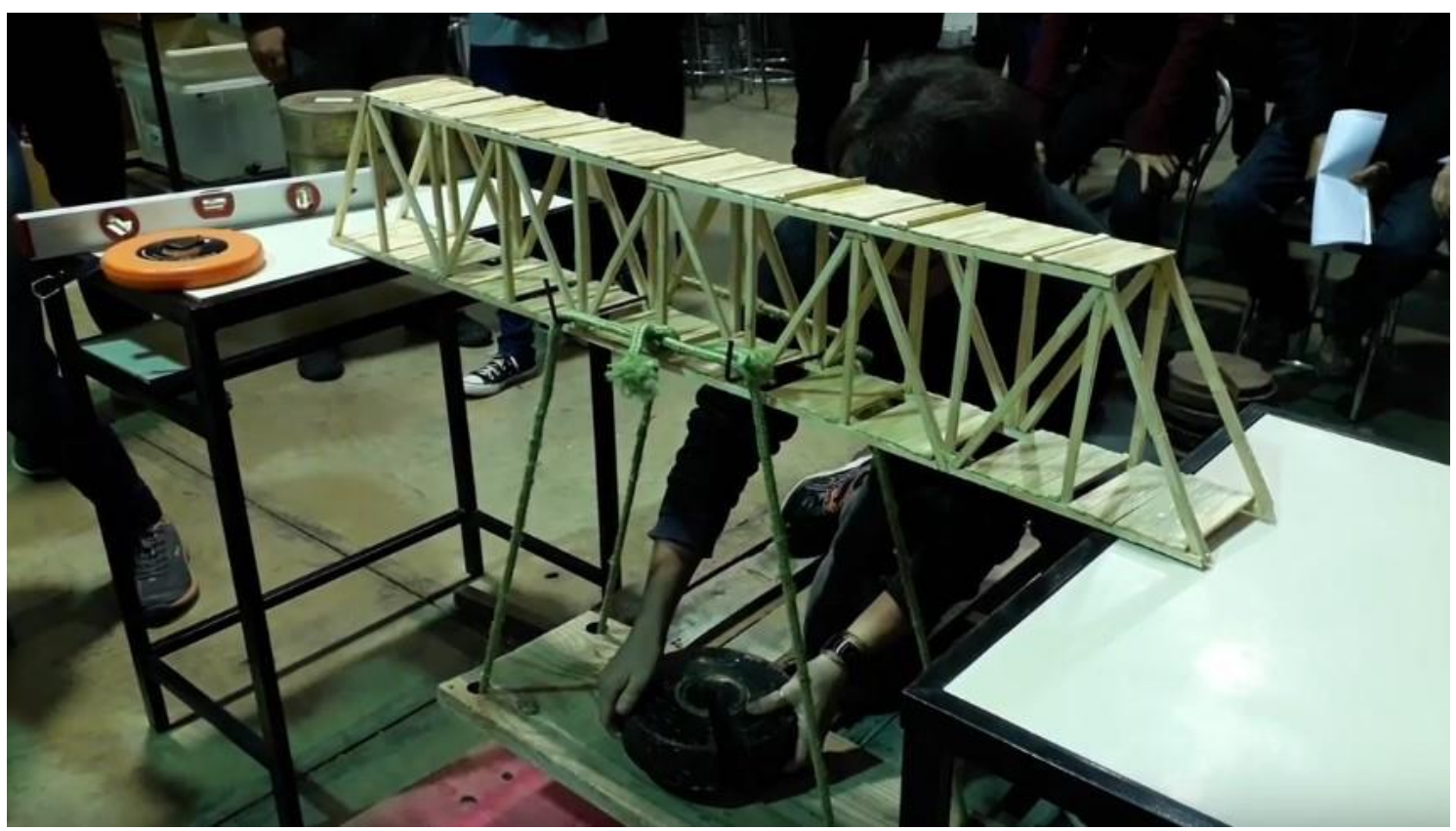

Fonte: Acervo CAEC - Competição de Pontes Semestre 2019/2.

Outra alteração importante para a organização, foi a mudança do espaço físico utilizado. A primeira e segunda edição da Competição de Pontes foram realizadas em locais abertos do campus, o intuito era chamar a atenção dos alunos que transitassem nas proximidades. Porém, esta escolha despendia de mais esforços por parte dos organizadores no deslocamento da estrutura necessária. São pesos, mesas, cadeiras, balança, dentre outros itens que fazem parte da estrutura do evento. Diante disso, a competição passou a ocorrer no Laboratório de Materiais de Construção Civil do campus. Ele já possuía grande parte da estrutura necessária, facilitando o deslocamento e permitindo que os organizadores se ocupasse com outras detalhes que poderiam elevar a qualidade da competição. A Figura 6 mostra a estrutura montada para a terceira edição da Competição de Pontes. 


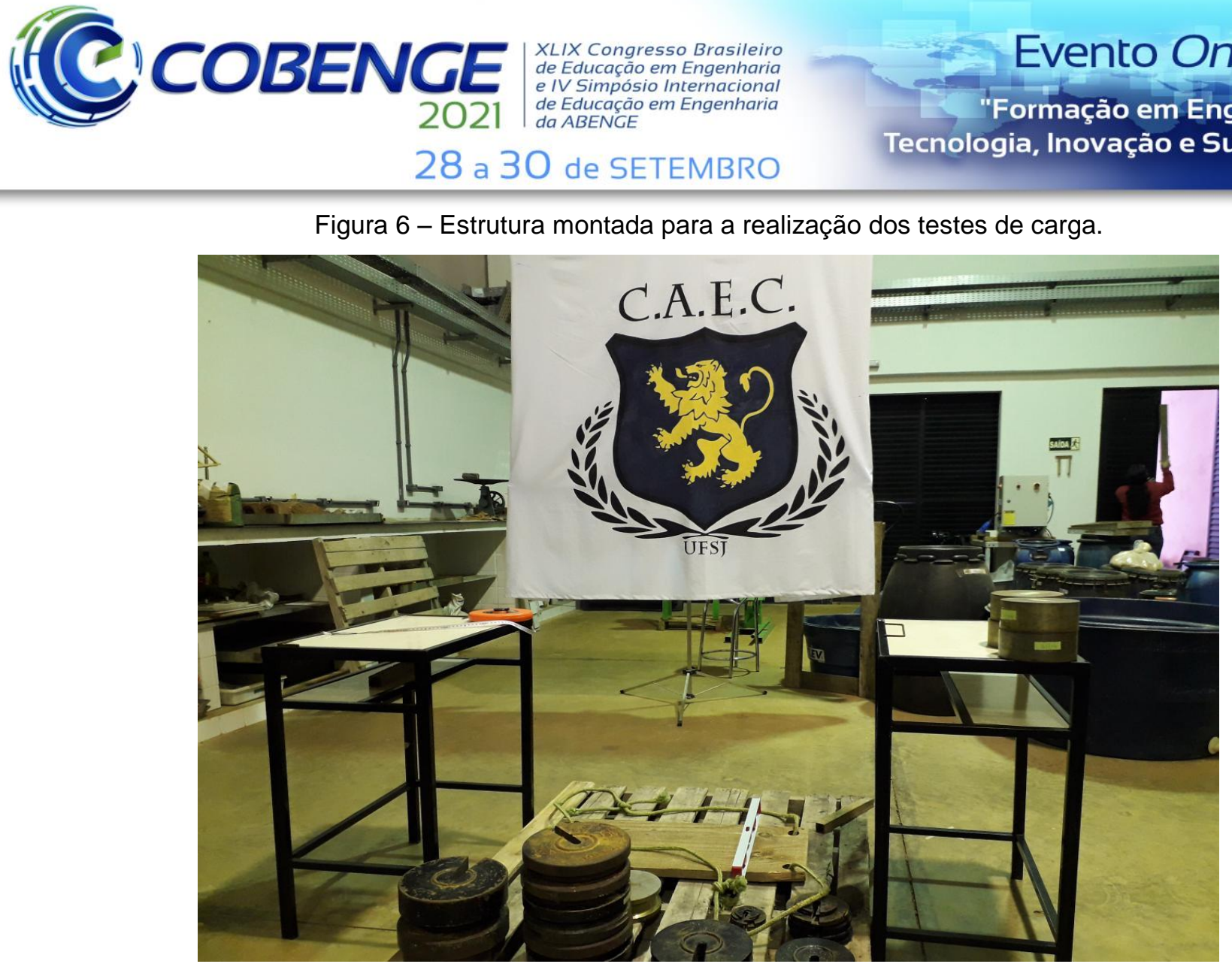

Fonte: Acervo CAEC - Competição de Pontes Semestre 2019/2.

\section{RESULTADOS E DISCUSSÕES}

Para avaliar a relevância do evento e seu papel no desenvolvimento do aprendizado dos alunos do curso de engenharia civil, foi aplicada uma pesquisa que contou com 24 respostas, segmentadas em três grupos de participantes: Organizadores, Competidores e Expectadores.

Dentre os organizadores do evento todos ( $100 \%$ das respostas) consideraram como uma experiência válida, fazer parte da comissão organizadora e que contribuiu para a sua formação acadêmica. Em relação aos expectadores, todos (100\% das respostas) consideraram que assistir a realização do evento foi uma experiência interessante.

E por fim, entre os competidores que responderam, todos (100\% das respostas) consideraram que desenvolver o projeto da construção de uma ponte de palitos de picolé contribuiu para sua formação acadêmica. $E$ também concordaram que o projeto permitiu aplicar uma função prática aos conceitos teóricos abordados dentro da sala de aula, colaborando para o seu aprendizado. Além de estimular de forma positiva sua criatividade, seu pensamento crítico e o trabalho em equipe.

Nas outras perguntas feitas aos competidores, procurou-se saber se eles sentiramse mais motivados e interessados em estudar as disciplinas da área de estruturas do curso de engenharia civil, com $87,5 \%$ concordando e $12,5 \%$ sendo indiferentes. Já em relação a melhoria do conhecimento no software Ftool, empregado para auxiliar nos cálculos do modelo da estrutura da ponte, $87,5 \%$ consideraram que houve uma melhora, enquanto que $12,5 \%$ foram indiferentes.

Todos os 24 participantes que responderam ao questionário reconheceram a importância do evento, para que ele tenha continuidade em mais edições.

No questionário, também foi dedicado um espaço para que estudantes e professores deixassem seus depoimentos. Foi selecionado alguns, que são apresentados a seguir: 
"Fui convidada gentilmente para participar, em duas ocasiões, como avaliadora no evento Competição de Pontes de palito de picolé, organizado pelo Centro Acadêmico de Engenharia Civil em conjunto com o professor Alexandre Galvão. Foi uma experiência muito prazerosa pois o evento proporciona um momento bastante interativo, descontraído. Além disso, esse tipo de atividade estimula a criatividade e a participação dos alunos em trabalhos em grupo. No caso específico da Competição de Pontes, incentiva a análise do comportamento estrutural e dos materiais sob a ação de carregamentos. Uma oportunidade bem dinâmica dos alunos ampliarem e aplicarem os conceitos absorvidos no curso de Engenharia Civil."

- Dalilah Pires Maximiano - Doutora em Engenharia Civil pela UFOP - Membro da Banca Avaliadora da Competição de Pontes (1 $1^{\mathrm{a}}$ e $3^{\mathrm{a}}$ Edição).

"É um evento importante para formação dos futuros engenheiros, pois são incentivados a aplicarem os conceitos teóricos nas práticas. Além de contribuírem para divulgar os conhecimentos no meio acadêmico e estimularem as habilidades de trabalharem em equipe, com os objetivos de obterem os melhores resultados."

- Hisashi Inoue - Doutor em Engenharia Civil pela UFRJ - Membro da Banca Avaliadora da Competição de Pontes (3ª Edição).

"O evento foi muito enriquecedor para todos os envolvidos, pois foi uma forma de aplicar de forma direta e prática, os conhecimentos adquiridos em diversas disciplinas do curso de engenharia civil."

- Andréia da Conceição de Faria - Técnica do Laboratório de Materiais de Construção Civil - Expectadora da Competição de Pontes.

"Participar da organização da competição de palitos foi uma experiência engrandecedora. A oportunidade de realizar um evento que leva os alunos a experimentar a prática do conhecimento aprendido em sala. Dentro da formação como futuros profissionais da engenharia a distância entre, o ambiente que nos espera após a formação exige conhecimento prático. São em eventos como este que agregam a formação e aprendizagem dos alunos. Fico muito feliz de poder ter participado da organização de eventos como este no curso. Sei que outras disciplinas poderiam ter competições assim para aumentar o engajamento dos alunos e engrandecer seus currículos."

- Wesley Renato Costa Pena - Graduando em Engenharia Civil pela UFSJ - Organizador da Competição de Pontes (1 ${ }^{\text {a }}$ Edição).

"A construção e projeto da ponte palitos me trouxe um engajamento maior no curso. Não existem muitas aplicações práticas do conhecimento adquirido nos primeiros períodos do curso. Esse trabalho foi o primeiro que me senti um engenheiro em formação. O projeto não é complicado, o complicado é a construção da ponte. Se atentar a cada detalhe no encaixe dos palitos, na cola, nas medidas... No momento da construção e tendo posse do conhecimento teórico é possível imaginar como ela vai entrar em colapso, onde é necessário mais atenção, isso faz toda a diferença. Foi o momento mais importante do curso pra mim. Recomendo a todos que façam com a maior dedicação possível. Sei que o tempo é corrido para todos mas é necessário esmero em tudo que fizer."

- Luiz Henrique de Carvalho - Graduando em Engenharia Civil pela UFSJ - Competidor da Competição de Pontes (1 ${ }^{a}$ Edição). 


\section{CONCLUSÕES}

A Competição de Pontes cumpriu com a sua proposta de estimular a capacidade de análise crítica dos estudantes envolvidos, possibilitando aplicação da teoria na prática. Avaliamos que o evento foi um sucesso conforme os resultados da pesquisa e depoimentos de discentes e docentes. Além disso, a repercussão entre os expectadores foi positiva como forma de entretenimento. Por estas razões, o centro acadêmico deveria continuar promovendo mais edições, sempre em busca de melhorias para a competição.

Após o estudo da competição algumas propostas de melhoria podem ser observadas. É interessante que seja usada uma aula da disciplina de Mecânica Vetorial como tutoria e apresentação da competição. Os organizadores do centro acadêmico podem preparar um conteúdo com dicas para a construção das pontes, demonstrar alguns modelos mais ousados de concepção estrutural para inspirar e motivar os competidores. O espaço pode ser usado também para explicação de detalhes importantes do edital.

Em relação ao teste de carga, pode ser montado um aparato que seja encaixado por meio de ganchos na aplicação das cargas. Esses ganchos ficariam fixados previamente por meio de cordas, para facilitar o preparo da ponte no momento do seu teste. Como também é interessante improvisar calços nas mesas, afim de que as pontes não deslizem sobre ela. Um vez que as pontes são calculadas para esforços axiais, caso haja um rotação, esta interfere diretamente no resultado do teste de carga.

A competição pode ser ampliada também para a modalidade de pontes hiperestáticas. Esse tipo de ponte suportaria mais peso e poderia proporcionar uma liberdade maior nas concepções estruturais. Assim, seriam duas modalidades, pontes isostáticas e pontes hiperestáticas. Da proposta também surge a oportunidade dos organizadores apresentarem um material para a disciplina de Estruturas Hiperestáticas do curso.

Assim, com estas melhorias a Competição de Pontes tende a crescer e proporcionar experiências cada vez mais impactantes para os graduandos do curso de Engenharia Civil da UFSJ.

\section{REFERÊNCIAS BIBLIOGRÁFICAS}

CAEC - CENTRO ACADÊMICO DE ENGENHARIA CIVIL. Acervo fotográfico:

Competição de Pontes dos semestres 2018/1 a 2019/2. UFSJ - Universidade Federal de São João Del Rei, Ouro Branco - MG.

\section{CAEC - CENTRO ACADÊMICO DE ENGENHARIA CIVIL. Regulamento: Competição} de pontes treliçadas de palito de picolé. UFSJ - Universidade Federal de São João Del Rei, Ouro Branco - MG, 2019.

KRIPKA, M. et al. Uma atividade didática elaborada por alunos para alunos: competição de guindastes de palitos de picolé. Educação \& Tecnologia, vol. 23, núm. 1, p. 59-66, jan./abr. 2018. Disponível em: https://periodicos.cefetmg.br/index.php/revistaet/article/view/741. Acesso em: 08 jan. 2021. 
MOREIRA, L. M. Aprendizagem baseada em projetos (abproj): estudo de caso com foco

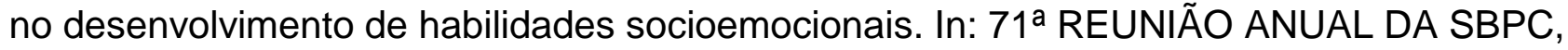
julho de 2019, Campo Grande - MS. Resumos dos Trabalhos. UFMS - Universidade Federal do Mato Grosso do Sul, 2019. Disponível em:

http://reunioessbpc.org.br/campogrande/inscritos/resumos/1382 1764f05f334c340fa7974 85dd6b21716e.pdf. Acesso em: 08 jan. 2021.

\title{
BRIDGES COMPETITION: STUDENTS IN FAVOR OF A TEACHING PROJECT
}

\begin{abstract}
The construction of reduced models of bridges on popsicle sticks has been applied as a teaching methodology in several Brazilian educational institutions. The present work reports the organization and development of a toothpick bridge competition in the civil engineering course at the Universidade Federal de São João Del Rei during the academic periods from 2018/2 to 2019/2. The initiative comes from students at the academic center of the course. A survey was carried out to prove the progress of the event and its potential to positively impact both organizing students and competitors. Its role as a learning method for consolidating knowledge related to the areas of structures, acquired by students in the course, through the application of theoretical concepts in practice, has been proven.
\end{abstract}

Keywords: Teaching. Engineering. Competition. Toothpick bridges. Academic Center. 